\title{
Ocean Cities : Environmental aspects
}

\author{
Dr. Jon Wonham \\ International Maritime Organization (IMO)
}

\section{INTRODUCTION}

For the purposes of this lecture I am assuming that an Ocean City is a community established on an artificial island and that it must incorporate measures into every aspect of its existence and activities that will provide the necessary degree of protection to the marine environment. It goes without saying that an integrated system of pollution control will be necessary and that assessments of environmental impact must simultaneously address the effects on air, water and terrestrial compartments.

An Ocean City cannot be self-sufficient in every material sense. It may be a dormitory area for workers in a nearby city, such as Tokyo, or a place for holidaying, recreation or retirement, such as Florida Keys. Presumably basic foodstuffs and retail goods will be shipped in but electricity may be generated in situ. Fresh water may be piped or shipped in, or desalinated in situ. Gas may be piped in or distributed in pressurized containers. Solid wastes may be partially disposed in situ, e.g. by incineration, with persistent and recyclable elements shipped for disposal to the mainland.

Transport connections with the mainland may take a variety of forms, e.g. road or rail tunnel, ship, hydrofoil or hovercraft, or by air (helicopter or conventional aircraft).

Nature conservation may have little meaning in the conventional sense, since an Ocean City is geared exclusively to meeting human needs. However, the location chosen for an Ocean City is frequently in areas such as the Great Barrier Reef and Florida whose principal attraction is their natural beauty. The conservation of areas adjacent to Ocean Cities, and the minimization of human impact will, therefore, frequently be of paramount importance.

In summary, the level of environmental awareness is now developed to the point that communities, wherever they are located, strive for living conditions which are relatively free from pollution and noise, but are, nevertheless, well served with amenities and services allowing good communication with other population centres. Residents of Ocean Cities expect no less for themselves, but must accept that the achievement of comparable or enhanced amenities within rather narrow confines may be considerably more expensive than a more conventional life style.

This lecture attempts to identify some of the environmental issues which Ocean Cities must confront, giving some thought as to their possible solution. This perspective comes from someone employed for twenty years in the maritime world, and may, or may not, throw new light on the subject matter.

\section{II — PURPOSE OF THE COMMUNITY}

The potential for environmental impact of an Ocean City will, of course, reflect the occupations and pursuits of residents and visitors to the community. The main possibilities are :

- Residential

- Touristic

- Mixed residential/touristic

- Any of the above, combined with service industries and/or small scale commercial and retailing undertakings.

Communities of all the above kinds will generate solid wastes and sewage, for which means of disposal must be found. Service industries may generate other wastes, e.g. waste oils, used batteries, obsolete domestic appliances, for which disposal arrangements must be made.

Ocean City is a relatively new concept requiring a substantial leap in the imagination. In the absence of an agreed definition, my own inclination is to think in terms of establishment of a community on an artificial island. It follows from this definition that system boundaries can be drawn, and environmental considerations emanating from the existence of that community, can be reasonably and rationally contemplated.

For the purpose of this lecture, environmental protection is considered under the following headings : purpose of the community ; management of wastes ; energy needs; transport needs; and conservation of the natural habitat.

Taking as a starting point the obligation under Article 208 of UNCLOS, 1982 that coastal States shall adopt laws and regulations to prevent, reduce and control pollution of the marine environment arising from artificial islands under their jurisdiction, the lecture draws upon the experience of the maritime community in regulating ship-generated marine pollution as a pointer to ways in which Ocean Cities may deal with similar problems. 
In planning an environmental control system for an Ocean City some early decisions will have to be made as to the intended purpose and character of the project. There would seem to be two basic choices : should the City be regarded as a satellite to an existing community, joined by an umbilical chord through which all the essentials of life flow in, and the waste products flow out, or should it develop as a viable community in its own right, with a mixture of human activities and the capability to be selfsufficient in a number of respects. The outcome of this choice will decide, for example, whether solid waste should be sorted into components for recycling and ultimate disposal or whether it is simply shipped to the mainland and dealt with under the parent community's waste disposal arrangements.

In the interests of environmentally sustainable development, I would hope that planning authorities would opt for the second alternative, viz. tending towards selfsufficiency. However, such questions will inevitably be influenced by purely economic considerations, in which scenario the shipping out of garbage in unsorted form may be the least-cost option. It will also be argued that the scale of Ocean Cities is too small to justify embarkation on elaborate waste segregation and recycling schemes. This can, however, be countered by the contention that residents and visitors to Ocean Cities are ready to pay a premium for the privilege, and that the costs of environmental self-sufficiency can be absorbed within that premium. Other factors, such as the costs of manual labour and whether the Ocean City should provide low cost living accommodation for workers and their families, and educational facilities, will also have a bearing on this difficult question.

Although economies can be expected through heat recovery from waste incinerators, and pay-back from recovered aluminium, steel and glass, it is unlikely to tip the purely financial equation in favour of self-sufficiency.

\section{MANAGEMENT OF WASTES}

Sewage will most likely be treated within the City limits, probably using anaerobic digesters, with incineration of residual sludge (with or without prior drying, in situ or on the mainland). Treatment of incinerator flue gases and precautions against odours from the sewage plant will be required. Disposal of liquid effluents must not breach coastal water quality standards and would almost certainly involve discharge through a submarine pipeline and diffuser at a location some distance from the City.

\subsection{Solid wastes}

Ocean Cities offer enormous potential for innovative approaches to solid wastes management. Bearing in mind the similarities between an Ocean City and a large cruise ship, both in terms of number of persons and the possibilities for treating the entire complex as a single entity from the planning viewpoint, I think it would be beneficial to highlight recent IMO thinking on shipboard waste management, as encapsulated in a draft Manual on Shipboard
Waste Management (1). These comments are confined to garbage, or solid waste, classified as :

— domestic solid waste

- maintenance waste

- cargo-associated waste.

Note: The term cargo would not be used in a shore-based situation, warehouse waste being more appropriate. However, the nature of the waste will be similar in many respects.

The IMO Manual lists the different wastes arising, thus allowing wastes with special disposal needs, e.g. medical wastes, to be identified. It also suggests pro forma quantities which can be expected per person per day. The Manual advocates preparation of a Waste situation report comprising :

- assessment of amounts and types of waste

- identification of sources of waste

- identification of when waste production arises

— pointing out responsibilities

and proposes that a source reduction strategy should be pursued by ship operators, thus minimizing the amount of waste generated. Suggestions for inclusion in such a strategy include :

- product substitution

- changing vessel equipment or vessel operating procedures

- supply handling practices (e.g. can supplies be delivered with reduced packaging ; can packaging be returned to the supplier)

- purchasing practices (e.g. can supplies be purchased/ordered with waste reduction product specifications, e.g. reusability, recycled materials content).

The Manual suggests that once source reduction, recycling and disposal methods have been explored, the ship operator should draw up a Waste Management Plan which :

- sets out discharge requirements of Annex $\mathrm{V}$ of the MARPOL Convention

- describes procedures for collecting, processing and storing garbage on board, and discharging garbage

- designates the person responsible for carrying out the Plan

- describes how crew members and passengers are to be made aware of the ship's waste management policies and practices

- describes procedures for notifying a port of the need for special services, e.g. disposal of medical and hazardous wastes.

IMO has also published a Manuel ( $\left.{ }^{2}\right)$ to assist port authorities in the collection and disposal of ship-generated wastes, giving guidance on estimating quantities of recyclable materials, finding a market for recyclables, etc.

Although referred to in the general context of solid waste management, references in footnotes 1 and 2 will be

(1) Document MEPC 37/16, submitted by Germany to the 37th session of the Marine Environment Protection Committee, 1115 September 1995.

( $\left.{ }^{2}\right)$ Comprehensive Manual on Port Reception Facilities, 1995 published by IMO, ISBN 92-801-1325-9, IMO Sales No. IMO$597 \mathrm{E}$. 
particularly relevant if the Ocean City has berthing provision for ocean-going ships, or possesses a marina for yachts and pleasure craft.

Success in managing all types of wastes from ships and pleasure craft is crucial in the present context. Since it is not possible to circumscribe the actions of persons on board such vessels to the same extent as persons ashore no effort should be spared in ensuring that marina users and "ships" passengers are aware of available waste collection facilities and that onerous penalties will be imposed for non-compliance.

\section{IV $\square$ ENERGY NEEDS}

The most likely location for Ocean Cities is in tropical or semi-tropical areas, although some temperate zones may have the necessary attributes. Presumably air conditioning and basic services such as lighting, refrigeration, catering, laundries, etc. will require a fairly substantial electricity supply. Even with a reliable connection to a mainland electricity supplier, consideration will likely be given to installing a stand-by generator which will operate automatically in the case of power failure. In cases where the public utility company's supply cannot be relied upon, an Ocean City may opt to be self-sufficient and instal its own power station. A whole raft of environmental considerations may then apply, particularly if mainland restrictions are applied to NOx, SOx and other components of the flue gas. A technical solution to NOx emissions is readily available and SOx may be controlled by choice of low Sulphur fuel, although a premium may be payable. Particulate emission and noise are both controllable, but would become less problematic if the power station is located some distance from the centre of population, for example, on its own island or offshore structure. Fuel storage tanks should be bunded in case of overfilling or equipment failure. These may seem very ordinary precautions, but it is surprising how many oil spills are the result of inept design and operating procedures. A relatively small oil spill under the circumstance could be catastrophic.

\section{$V \square$ TRANSPORT NEEDS}

Some environmental aspects associated with marinas and the berthing of ships has been touched upon. One can conceive of passenger linkage with the mainland by a rail or road tunnel, or by bridge or causeway. From the environmental viewpoint, a rail link (preferably electric) would have a lesser impact. If road vehicle access is to be allowed, it should be restricted to one or two parking areas at the City's periphery. Vehicle transport within Ocean Cities should be limited to essential services, with segregated access ways so as not to encroach upon pedestrian areas. Small electrically powered vehicles and pedestrian controlled trollies can be used for transporting elderly or disabled people and luggage. The environmental impact of such an arrangement would be minimal.

If access to road vehicles is allowed, and to an extent this applies to rail traffic, there will inevitably be small leakages of oil and hydraulic fluid that will accumulate and eventually find their way into surface water run-off. Under circumstances where maintenance of a pristine marine environment is essential, arrangements should be made in the design of civil engineering works either for water run-off to be channelled to a dedicated water purification plant or to be discharged into the sea through a submarine pipeline at a point some distance from the shore.

\section{CONSERVATION OF THE NATURAL HABITAT}

This is an enormous subject, and I will only touch upon it here. Furthermore, international bodies such as the International Union for Conservation of Nature and Natural Resources (IUCN) and World Wide Fund for Nature (WWF) are recognized as having competence in this area. Ocean Cities will, inevitably, create problems in managing and conserving the natural habitat. There are many reports of glass-bottomed tourist boats damaging coral reefs with their anchors, and of divers and snorkellers taking coral as souvenirs. No doubt strict control of activities by conservation managers can prevent the worst excesses, but the sheer pressure of numbers may also exact a toll. References should be made here to the ways in which the Great Barrier Reef National Park Authority and other similar bodies are handling such matters.

There is scope here for a particularly sensitive sea area (PSSA) to be given additional protection from shipping activities through recognition of the area by IMO. So far, this has only happened in the context of the Great Barrier Reef.

There may, however, be more insidious ways in which human activities are destroying natural habitats and thus undermining the raison d'être for Ocean Cities. Substantial areas of coral reef are dying in areas adjacent to major tourist and residential areas such as Florida and the Caribbean. This may be attributable to inputs of nutrient from agricultural run-off and discharges from municipalities. Ocean Cities are too small in number to add significantly to this problem. They may, nevertheless, cause deterioration of the micro-environment in their own vicinity, and would certainly be less attractive to residents and visitors if located in an area of general decline.

This is an added incentive to search for solutions to long-term problems which threaten the marine environment. 